\title{
USE OF HYDROGEN-CONTAINING REM-BASED ADDITIONS IN DESIGNING RE-Fe-B MAGNETIC MATERIALS
}

\author{
${ }^{1}$ Kateřina SKOTNICOVÁ, ${ }^{2}$ Natalia B. KOLCHUGINA, ${ }^{2}$ Gennady S. BURKHANOV, \\ ${ }^{1}$ Tomáš ČEGAN, ${ }^{1}$ Miroslav KURSA, ${ }^{3}$ Alexander A. LUKIN, ${ }^{1}$ Ondřej ŽIVOTSKÝ, \\ ${ }^{2,3}$ Pavel A. PROKOFEV, ${ }^{2}$ Nikolay A. DORMIDONTOV, ${ }^{1}$ Jan JUŘICA \\ ${ }^{1}$ VSB - Technical University of Ostrava, Faculty of Materials Science and Technology, 70800 Ostrava, \\ Czech Republic,EU, katerina.skotnicova@vsb.cz \\ ${ }^{2}$ Baikov Institute of Metallurgy and Materials Science, Russian Academy of Sciences, 119334 Moscow, \\ Russia; nkolchugina@imet.ac.ru \\ 3Joint stock company «Spetsmagnit»,127238 Moscow, Russia; pav3387@yandex.ru
}

https://doi.org/10.37904/metal.2020.3591

\begin{abstract}
The focusing of new technologies on the formation of inhomogeneous distributions of heavy rare-earth metals (REMs) in hard magnetic Nd-Fe-B materials is of scientific importance for increasing their functional properties, along with preserving existing sources of heavy REMs. The manufacturing process for these materials includes strip-casting, hydrogen decrepitation, and treatments in a hydrogen atmosphere, as well as high-energy milling combined with mechanical alloying of multicomponent powder mixtures. The role of alloying REMs and their alloys with transition metals on the formation of phase composition, microstructure, fine structure of grains, and the hysteretic properties of hard magnetic $\left(\mathrm{RR}^{\prime}\right)_{2} \mathrm{Fe}_{14} \mathrm{~B}$-based materials were investigated. These addition were introduced in the form of hydrides or hydrogenated alloys $\left(\mathrm{TbH}_{\mathrm{x}}, \mathrm{DyH}_{\mathrm{x}}, \mathrm{ScH}_{\mathrm{x}}, \mathrm{Tb}_{3}(\mathrm{Co}, \mathrm{Cu}), \mathrm{Dy}_{3}(\mathrm{Co}, \mathrm{Cu})\right)$ to initial $\mathrm{Nd}(\mathrm{Pr})-\mathrm{Fe}-\mathrm{B}-$ based powder mixtures in the course of their mechanical activation. The new knowledge about the formation of the structured state of $\left(\mathrm{RR}^{\prime}\right)_{2} \mathrm{Fe}_{14} \mathrm{~B}$-phase grains, namely, the formation of compositional inhomogeneities of heavy REMs within grains was obtained. The core-shell grain structure so formed and the nonuniformity of the main hard magnetic phase lead to increases in the structure-sensitive magnetic parameters and to their higher stability during low-temperature annealing. The powder-blending manufacturing process allows us to prepare magnets with a wide range of hysteretic characteristics using unified initial $\mathrm{Nd}$ Fe-B strip-casting alloys.
\end{abstract}

Keywords: Nd-Fe-B magnets, hydride, microstructure, REM distribution, magnetic properties.

\section{INTRODUCTION}

Sintered $\mathrm{Nd}_{2} \mathrm{Fe}_{14} \mathrm{~B}$-based permanent magnets are widely used in technological applications because of their high maximum energy product $(B H)_{\max }$, remanence $B_{\mathrm{r}}$, induction coercive force ${ }_{\mathrm{b}} H_{\mathrm{c}}$, and magnetization coercive force ${ }_{j} H_{c}$. To increase ${ }_{j} H_{c}$, which determines the time-temperature stability of sintered magnets, the $\mathrm{Nd}_{14-15} \mathrm{Fe}_{\text {bal }} \mathrm{B}_{6-8}$ (at\%) base composition is traditionally alloyed with $\mathrm{Dy}$ and $\mathrm{Tb}$ (to increase the anisotropy field $H_{a}$, which rises with increasing heavy rare-earth metal (REM) fraction; in this case, the remanence decreases as the coercivity increases), $\mathrm{Ti}, \mathrm{V}$, and $\mathrm{Nb}$ (to prevent grain growth during sintering), and $\mathrm{Al}, \mathrm{Ga}$, and $\mathrm{Cu}$ (to modify the structure of the grain-boundary phases) using the following technological processes: strip-casting, hydrogen decrepitation, mechanical alloying, diffusion saturation of the magnet surface with REMs (Dy, Tb) and subsequent heat treatment at $1075-1175 \mathrm{~K}$, and multi-stage heat treatments at temperatures of $750-1275$ K [1-4]. 
Scarce resources of heavy REMs determine the search for options to reduce the usage of these metals. The alloying of Nd-Fe-B main compositions with REMs added in the form of hydrides was realized in References 58. These studies showed the efficiency of application of $\mathrm{Nd}, \mathrm{Pr}$, and Dy hydrides in powder mixtures for manufacturing permanent magnets.

The focusing of new technologies on the realization of the inhomogeneous distribution of heavy REMs in hard magnetic $\mathrm{Nd}-\mathrm{Fe}-\mathrm{B}$ materials is of scientific importance for increasing their functional properties, along with preserving existing sources of heavy REMs [1-6]. The approach used by us, namely, the alloying of powder mixtures with REM hydrides and hydrogenated REM-(M) $(R E M=D y, T b$, and $M=C u, C o)$ compositions, allows us to form a structured state of the main hard magnetic phase at the expense of the intra-grain heterogeneous distribution of light and heavy REMs. This approach is original and has been shown to be valid [6-8]. The milling of blended powder compositions (the base Nd-Fe-B alloy and different REM-(M)-H additions) and subsequent sintering allow the grain-boundary diffusion of heavy REMs and grain structuring to be realized and the materials with a pre-set combination of hysteretic properties required for different applications to be prepared.

The present study is focused on the effect REM-based powders $\left(\mathrm{TbH}_{x}, \mathrm{DyH}_{x}, \mathrm{ScH}_{x}, \mathrm{~Tb}_{3} \mathrm{Co}_{0.6} \mathrm{Cu}_{0.4}\right.$, $\left.\mathrm{Dy}_{3} \mathrm{Co}_{0.6} \mathrm{Cu}_{0.4}\right)$ added to $\mathrm{Nd}-\mathrm{Fe}$-B-based powder mixtures on the formation of the phase composition, microstructure, fine structure of grains, and hysteretic properties of hard magnetic ( $\left(R^{\prime}\right)_{2} \mathrm{Fe}_{14} \mathrm{~B}$-based materials.

\section{EXPERIMENTAL}

The base Nd-24.0, Pr-6.5, Dy-0.5, B-1.0, Al-0.2, Fe-balance alloy (wt\%) was prepared by the strip-casting technique and subjected to hydrogen decrepitation during heating to $270{ }^{\circ} \mathrm{C}$ in a hydrogen flow at a pressure of $0.1 \mathrm{MPa}$ and to subsequent holding at this temperature for $1 \mathrm{~h}$.

Terbium, dysprosium, and scandium hydrides $\left(\mathrm{RH}_{2-3}\right)$ were obtained by direct reaction of gaseous hydrogen with Tb, Dy, or Sc metal of $99.9 \%$ purity using a glass Sieverts-type apparatus. The hydrogenation was carried out at $500-700{ }^{\circ} \mathrm{C}$ using pure hydrogen at a pressure of up to $0.1 \mathrm{MPa}$. Once synthesized, the samples were homogenized for $72 \mathrm{~h}$ at $350^{\circ} \mathrm{C}$.

The $\mathrm{Dy}_{3}\left(\mathrm{Co}_{1-x} \mathrm{Cu}_{x}\right)$ and $\mathrm{Tb}_{3}\left(\mathrm{Co}_{1-x} \mathrm{Cu}_{x}\right)$ alloys with $x=0.4$ were prepared by arc melting of the starting components (distilled Dy and Tb of $99.9 \%$ purity, electrolytic Co of $99.5 \%$ purity), and oxygen-free $\mathrm{Cu}$ in an argon atmosphere using a water-cold copper bottom and a nonconsumable tungsten electrode. The ingots subjected to homogenizing annealing at $600{ }^{\circ} \mathrm{C}$ for $90 \mathrm{~h}$ were found to be multiphase and contained Dy(or $\mathrm{Tb})_{3}(\mathrm{Co}, \mathrm{Cu})$ (base phase) and $\mathrm{Dy}($ or $\mathrm{Tb})(\mathrm{Cu}, \mathrm{Co})$ and $\mathrm{Dy}(\mathrm{or} \mathrm{Tb})_{12}(\mathrm{Co}, \mathrm{Cu})_{7}$ compounds. The ingots were subjected to hydrogenation in accordance with the aforementioned regimes. Following hydrogenation, the presence of REM hydrides and a fine $\mathrm{Co}+\mathrm{Cu}$ mixture was demonstrated [9].

The hydrogen-decrepitated strip-cast alloy and REM hydrides or hydrogenated compounds (1-4 wt \%) were mixed and subjected to fine milling for 40 min using a vibratory mill and an isopropyl alcohol medium until an average particle size of $3 \mu \mathrm{m}$ was reached. Following wet compaction of the pulp in a transverse magnetic field of $1500 \mathrm{kA} / \mathrm{m}$, blanks of magnets were sintered at $1080^{\circ} \mathrm{C}$ for $2 \mathrm{~h}$. The magnets were further subjected to the optimal heat treatment $\left(500{ }^{\circ} \mathrm{C}\right.$ for $2 \mathrm{~h}$ ) and the low-temperature heat treatment: $20^{\circ} \mathrm{C} \rightarrow(40 \mathrm{~min}) \rightarrow$ $500{ }^{\circ} \mathrm{C}(20 \mathrm{~min}) \rightarrow(6 \mathrm{~h}) \rightarrow 400{ }^{\circ} \mathrm{C}(10 \mathrm{~h})$.

An QUANTA 450 FEG high-resolution field emission gun scanning electron microscope (SEM, FEI Company, USA) equipped with an energy-dispersive spectroscopy (EDS, EDAX, USA) microprobe was used to investigate the structure, chemical composition, and distribution of magnet components (X-ray mapping). The hydrogen and oxygen contents were controlled using an $\mathrm{ONH}-2000$ analyzer (ELTRA, Germany). The magnetic properties of the permanent magnet were measured at room temperature (RT) using an automatic hysteresisgraph. Auger electron spectroscopy (AES) was performed using a JAMP 9500F spectrometer 
(JEOL, Japan) equipped with an INCA PentaFETx3 energy-dispersive analyzer (Oxford Instruments, United Kingdom) and a $\mu$ IFG iMOXS microfocused X-ray tube (Institute for Scientific Instruments, Germany).

The total oxygen content in all samples was below $5000 \mathrm{ppm}$. The low hydrogen content of $\sim 3 \mathrm{ppm}$ indicates the complete decomposition of hydride-containing compounds and removal of hydrogen during sintering.

\section{EXPERIMENTAL}

\subsection{Investigation of alloying element distribution}

Experiments with hydrides and hydrogenated compounds, which were added at the milling stage, were performed in order to realize the optimal microstructure, heterogeneous distribution of heavy REMs within a grain, and economically alloyed composition of magnets, which assume, in particular, the accumulation of heavy REMs (Dy, Tb) within grains at the near-boundary areas. Such a heavy-REM distribution allows us to: (1) increase locally the coercive force and decrease the probability of formation of reverse domains at grain boundaries; (2) limit the substitution of heavy REMs for $\mathrm{Nd}$ in the matrix phase and, thus, to decrease the probability of lowering the magnetization and remanence; and (3) decrease the quantity of heavy REMs required to achieve the given increase in the coercive force. The mechanism of formation of the high-coercivity state in $\mathrm{Nd}_{2} \mathrm{Fe}_{14} \mathrm{~B}$-based materials is well known and is due to the nucleation of reverse domains in magnetically isolated small grains. The coercivity can appear also when introducing pinning centres against the magnetic domain wall motion. The pinning force appears when there is a large local change in the magnetocrystalline anisotropy constant in a narrow region, and the probability of this mechanism occurring in $\mathrm{Nd}-\mathrm{Fe}-\mathrm{B}$ magnets is considered [10]. For this reason, we have studied in detail the distribution of heavy REMs in magnets prepared with powder mixtures containing REM hydrides and hydrogenated $\mathrm{Dy}(\mathrm{Tb})-\mathrm{Co}-\mathrm{Cu}$ compositions.

Precise studies of the structures of magnets prepared with heavy REM hydrides showed the existence of specific distributions of the heavy REMs within grains. The presence of reactive $\mathrm{Dy}(\mathrm{Tb})$ powder (coming from $\mathrm{Dy}(\mathrm{Tb}) \mathrm{H}_{2}$ thermally destroyed during sintering) determines the diffusion of $\mathrm{Dy}(\mathrm{Tb})$ atoms to the 2-14-1 phase lattice, the atomic radii of which are lower than that of $\mathrm{Nd}$ atoms. This is accompanied by ousting of $\mathrm{Nd}$ atoms to the peripheral areas of grains. Since the diffusion coefficient of $\mathrm{Nd}$ atoms is lower than that of $\mathrm{Tb} /(\mathrm{Dy})$ atoms [11], the diffusion of $\mathrm{Dy}(\mathrm{Tb})$ is more substantial. Such unequal diffusion flows of atoms lead to inhomogeneous $\mathrm{Dy}(\mathrm{Tb})$ and $\mathrm{Nd}(\mathrm{Pr})$ distributions over the 2-14-1-phase grains.

The Tb distribution was investigated by Auger electron spectroscopy. Figure 1 shows (a) SEM image (secondary electron image (SEI)) of the surface of the Nd-Fe-B magnet with $4 \mathrm{wt} \% \mathrm{TbH}_{2}$ and (b, c) the $\mathrm{Tb}$ distribution. As can be seen, the enrichment of $\mathrm{Nd}_{2} \mathrm{Fe}_{14} \mathrm{~B}$-phase grain boundaries in $\mathrm{Tb}$ is observed (shown by arrows in Figure 1b). Moreover, the existence of some "substructure" in the Tb distribution can be noted (Figure 1c): the Tb-enriched and Tb-depleted areas are shown by the geometric figures. It is likely that such a Tb distribution formed during sintering is the result of the preparation process realized with hydride-containing powder. The size of the "subgrains" is $\sim 1-1.5 \mu \mathrm{m}$ (shown by the rhombus in Figure 1c); the size of inhomogeneities within the "subgrains" is $30-150 \mathrm{~nm}$ (shown by the circle and oval). An analogous "composite" structure in Nd-Dy-Tb-Fe-B magnets was simulated by Kawasaki, et al. [12] and the efficiency of such a composite structure was proved.

A Tb-rich shell and an inhomogeneous Tb distribution within the large grains (structuring of 2-14-1 phase) were found. The latter finding, namely, the concentration inhomogeneity, can be considered as resulting in the creation of pinning centers of domains walls and, therefore, the hardening of the magnetic phase. In most studies, the mechanism by which the coercive force increases is considered from the viewpoint of grainboundary phases and the so-called core-shell structure. We, however, also consider the problem from the viewpoint of the structuring of the main magnetic phase. 
The distribution of REMs, Co, and $\mathrm{Cu}$ in the 2-14-1 grains and in the intergranular Nd-rich phases in the sintered magnets prepared from the powder mixtures with 2 wt\% $\mathrm{Dy}_{3}(\mathrm{Co}, \mathrm{Cu})$ (or $\mathrm{Tb}_{3}(\mathrm{Co}, \mathrm{Cu})$ ) addition was also studied using X-ray mapping (Figure 2). The heterogeneous Dy or Tb distribution within the 2-14-1 grains can be observed. The depletion of triple junctions in $\mathrm{Co}$ and their enrichment in $\mathrm{Cu}$ in the case of $\mathrm{Dy}(\mathrm{Tb})_{3}(\mathrm{Cu}, \mathrm{Cu})$ additions should be noted.
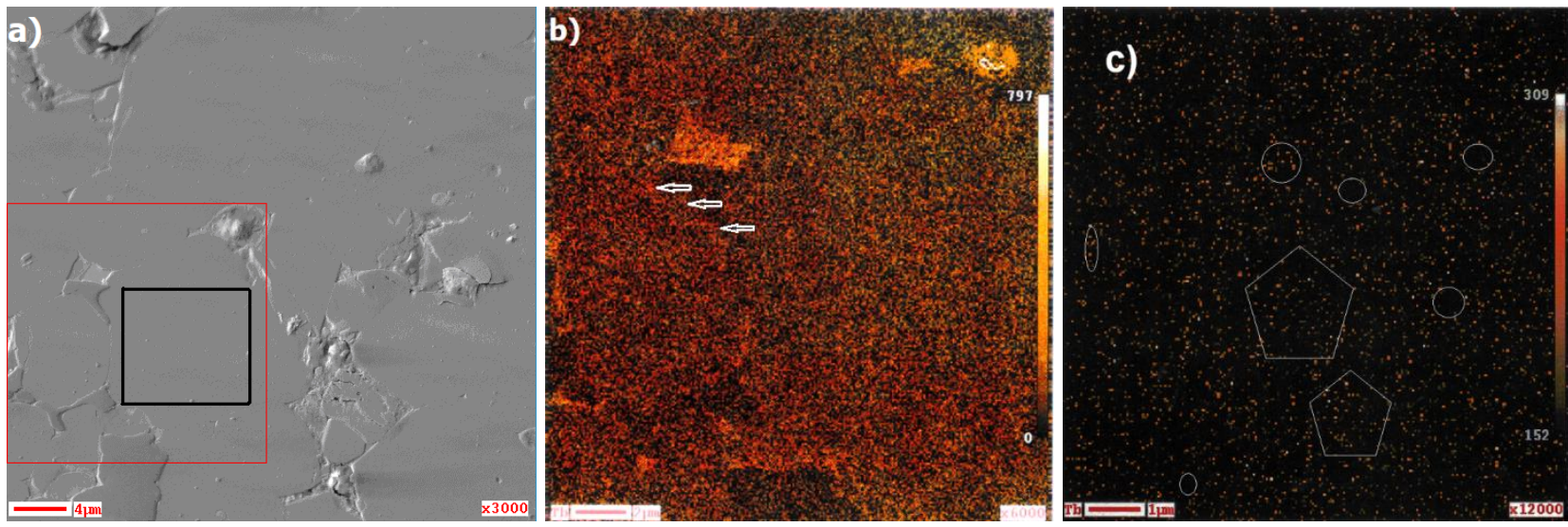

Figure 1 a) Microstructure of Nd-Fe-B magnet prepared with 4 wt\% $\mathrm{TbH}_{2}$ (SEI) and b, c) Tb distribution (AES, areas agree with red square and black square respectively)
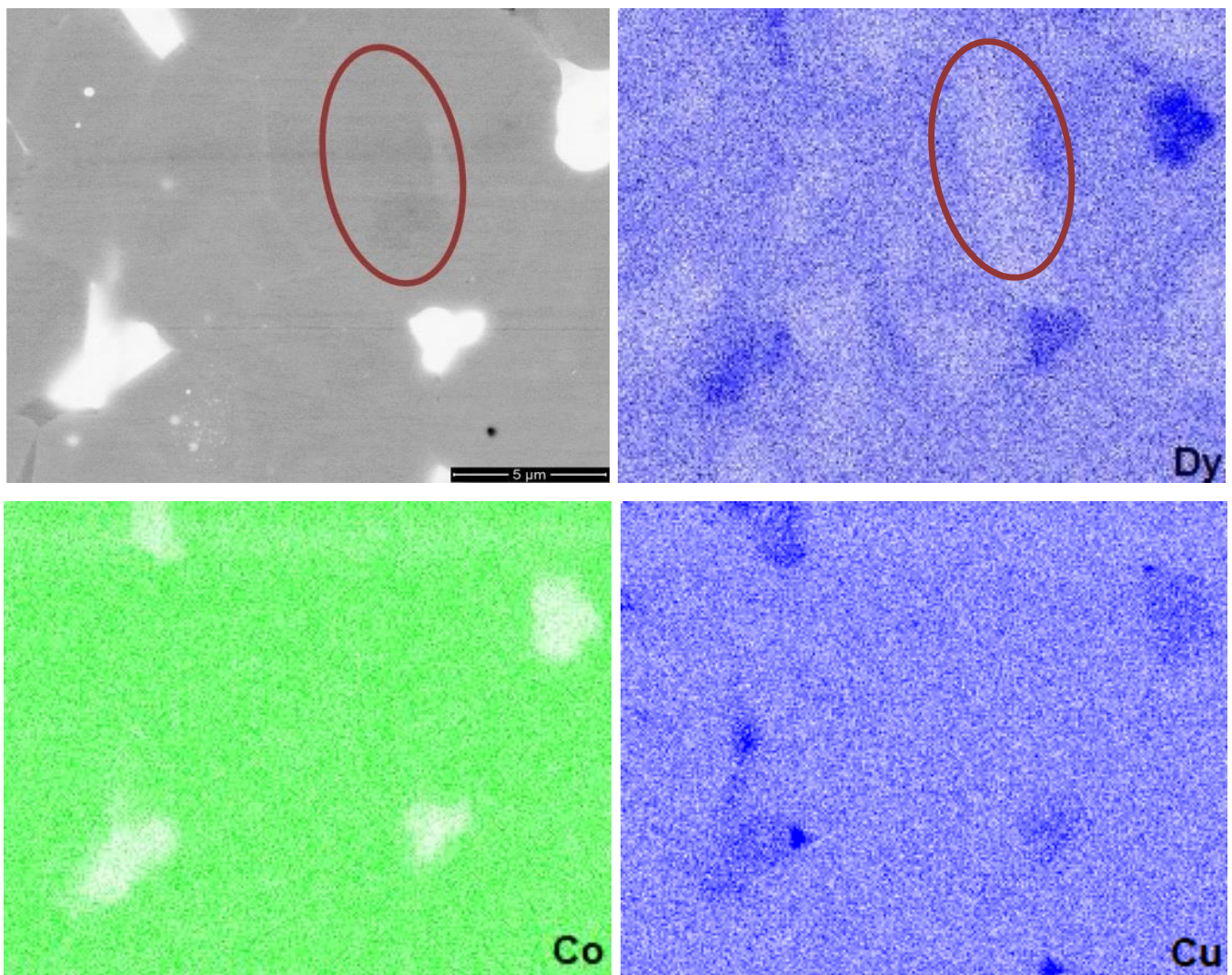

Figure $2 \mathrm{X}$-ray elemental mapping of $\mathrm{Co}, \mathrm{Cu}$, and $\mathrm{Dy}$ in 2-14-1 grains and in the intergranular phases of the $\mathrm{Nd}-\mathrm{Fe}-\mathrm{B}$ sintered magnet prepared from the powder mixture with $2 \mathrm{wt} \%$ of hydrogenated $\mathrm{Dy}_{3}\left(\mathrm{Co}_{0.6} \mathrm{Cu}_{0.4}\right)$ addition

The other components of the $\mathrm{Tb}$ (or Dy) ${ }_{3} \mathrm{Co}_{0.6} \mathrm{Cu}_{0.4} \mathrm{H}_{x}$ composition, i.e., $\mathrm{Cu}$ and $\mathrm{Co}$, are also useful additions for $\mathrm{Nd}-\mathrm{Fe}-\mathrm{B}$-based magnets. The role of $\mathrm{Cu}$ in the grain-boundary restructuring of $\mathrm{Nd}-\mathrm{Fe}-\mathrm{B}$ sintered magnets was 
considered in References 13-14. According to the data, $\mathrm{Cu}$ improved the wettability of the $\mathrm{Nd}_{2} \mathrm{Fe}_{14} \mathrm{~B}$ grains by forming an intergranular phase. The positive effect of $\mathrm{Co}$ on the coercivity of $\mathrm{Nd}-\mathrm{Fe}-\mathrm{B}$ magnets was reported in References [15-17].

The effect of scandium hydride on the structural state of sintered magnets differs from that of terbium and dysprosium hydrides. Scandium can act as a component, which restricts the $\mathrm{Nd}_{2} \mathrm{Fe}_{14} \mathrm{~B}$-phase grain growth by analogy with $\mathrm{Ti}, \mathrm{Nb}, \mathrm{Mo}$, and $\mathrm{V}$.

Scandium was found preferentially within intergranular phases (black particles in Figure 3), because Sc does not diffuse into 2-14-1 grains despite its smaller atomic radius [18]. It is evident that the Sc-based phases are characterized by an increased boron content, corresponding to the assumption that $\mathrm{Sc}$ reacts with $\mathrm{B}$ during sintering (Figure 3). Also, we have demonstrated that the presence of $\mathrm{Sc}$ coming from $\mathrm{ScH}_{\sim 2}$ restricts grain growth.
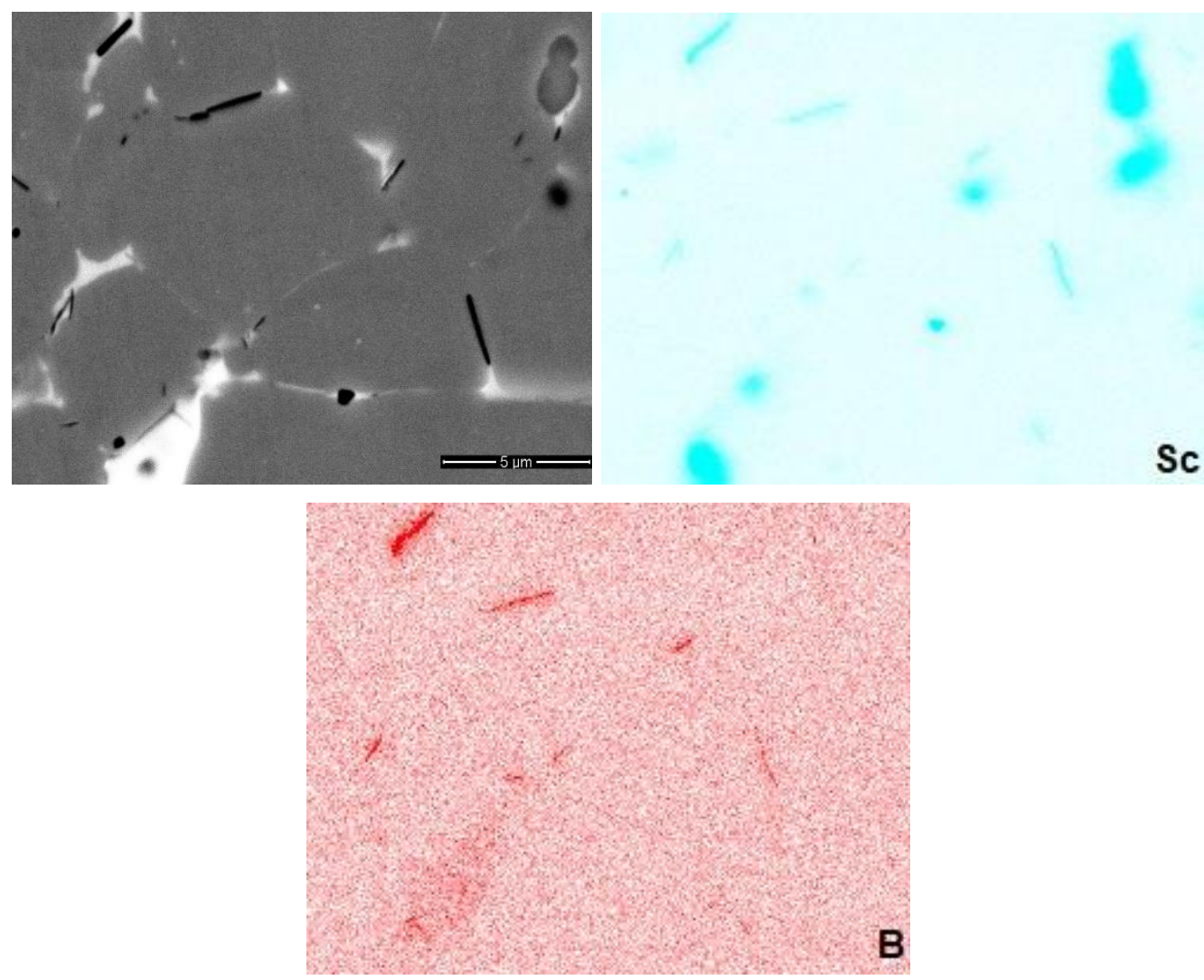

Figure $3 \mathrm{X}$-ray mapping of $\mathrm{Sc}$ and $\mathrm{B}$ in Nd-Fe-B sintered magnet prepared from the powder mixture with 1 wt $\% \mathrm{ScH}_{x}$ addition

\subsection{Investigation of alloying element distribution}

Table 1 shows the magnetic properties of sintered magnets prepared with hydride or hydrogenated compounds. According to the data, alloying with 2 and $4 \mathrm{wt} \% \mathrm{TbH}_{2}$ leads to an increase in the coercive force to 1520 and $1900 \mathrm{kA} / \mathrm{m}$, i.e., by $52 \%$ and $90 \%$, respectively. Simultaneously, the magnitudes of $B_{\mathrm{r}}$ and $(B H)_{\max }$ decrease to $1.30 \mathrm{~T}(\sim 4.4 \%)$ and $328 \mathrm{~kJ} / \mathrm{m}^{3}(8 \%)$, respectively, for $2 \mathrm{wt} \% \mathrm{TbH}_{2}$ addition and to $1.22 \mathrm{~T}(10 \%)$ and $286 \mathrm{~kJ} / \mathrm{m}^{3}(20 \%)$, respectively, for $4 \mathrm{wt} \% \mathrm{TbH}_{2}$ addition.

The data on the hysteretic characteristics of the magnets indicate that the value of ${ }_{j} H_{c}$ is disproportionately high with respect to the added Tb content. This fact is explained by the existence of the well-known structure of the main magnetic-phase grains, namely, the Tb-enriched shell and the Tb-depleted core of the grains. Moreover, the presence of submicron-sized inhomogeneities, namely, "areas" enriched in Tb (depleted of Nd 
$(\mathrm{Pr}))$, which were found within the 2-14-1 magnetic-phase grains, is likely can be involved in the explanation of this phenomenon.

Table 1 Magnetic characteristics of Nd-Fe-B magnets prepared with hydride or hydrogenated compounds; $B_{\mathrm{r}}$ - remanence of magnetic flux density; ${ }_{j} H_{\mathrm{c}}$ - coercivity of magnetic polarization; $H_{\mathrm{k}}$ - parameter adopted as a criterion of coercivity (i.e., the magnetic field determined at $0.9 \times B_{i} ;(B H)_{\max }-$ maximum energy product).

\begin{tabular}{|c|c|c|c|c|}
\hline \multirow{2}{*}{ Addition/annealing conditions } & $B_{r}$ & ${ }_{\mathrm{j}} H_{\mathrm{c}}$ & $H_{\mathrm{k}}$ & $(B H)_{\max }$ \\
\hline & $(\mathrm{T})$ & $(\mathrm{kA} / \mathrm{m})$ & $(\mathrm{kA} / \mathrm{m})$ & $\left(\mathrm{kJ} / \mathrm{m}^{3}\right)$ \\
\hline 2 wt $\%$ DyH $\mathrm{H}_{x} / \mathrm{optimal} \mathrm{HT}$ & 1.29 & 1309 & 1262 & 322 \\
\hline 2 wt $\%$ TbH ${ }_{x} /$ optimal HT & 1.30 & 1520 & 1440 & 328 \\
\hline $4 \mathrm{wt} \% \mathrm{TbH}_{x} /$ optimal HT & 1.22 & 1900 & 1760 & 286 \\
\hline 2 wt\% Dy ${ }_{3} \mathrm{Co}_{0.6} \mathrm{Cu}_{0.4 \mathrm{H}} \mathrm{H}_{x}$ optimal HT & 1.34 & 1120 & 968 & 336 \\
\hline $2 \mathrm{wt} \% \mathrm{~Tb}_{3} \mathrm{Co}_{0.6} \mathrm{Cu}_{0.4} \mathrm{H}_{x} /$ optimal HT & 1.35 & 1336 & 1200 & 360 \\
\hline $2 \mathrm{wt} \% \mathrm{~Tb}_{3} \mathrm{Co}_{0.6} \mathrm{Cu}_{0.4} \mathrm{H}_{x} /$ optimal + low-temperature HT & 1.35 & 1480 & 1330 & $\geq 360$ \\
\hline
\end{tabular}

Studies of the stability of structure-sensitive parameters of sintered magnets, namely, the coercive force ${ }_{j} H_{c}$, to low-temperature heat treatments (annealing at temperatures below the optimal heat treatment temperature $\left(500{ }^{\circ} \mathrm{C}\right)$ ) show an increase in the coercive force (Table 1) in the case of the application of hydrogenated $\mathrm{Tb}_{3} \mathrm{Co}_{0.6} \mathrm{Cu}_{0.4}$. This fact is not typical of sintered Nd-Fe-B magnets, which usually demonstrate a drop (or constancy) of the coercive force after low-temperature heat treatments at $350-450{ }^{\circ} \mathrm{C}$ [6-8]. The constancy of the coercive force during low-temperature annealing was previously observed with $\mathrm{DyH}_{2}$ addition to the powder mixture [10]. This was explained by the Invar effect, which is due to changes in crystal lattice rigidity owing to structuring of the 2-14-1 phase alloyed with Dy via grain-boundary diffusion (GBD). Thus, in the case of alloying the 2-14-1 phase with heavy REMs by GBD using $\mathrm{Tb}_{3} \mathrm{Co}_{0.6} \mathrm{Cu}_{0.4} \mathrm{H}_{x}$, no decrease in ${ }_{j} H_{c}$ or $H_{k}$ occurred, whereas the increase in these parameters can be related to the effect of $\mathrm{Cu}$ in the intergranular REM-rich phase and also to Co [17].

\section{CONCLUSIONS}

In summary, our studies of Nd-Fe-B magnets prepared from strip-cast alloys show that $\mathrm{Tb}$ (Dy) alloying (REM hydride or hydrogenated compounds added to powder mixture) is expected to result in the formation of the core-shell structure of 2-14-1 phase grains and a specific distribution of rare-earth components, which allows us to assume the realization of domain wall pinning, along with the suppression of the nucleation of reverse domains. The efficient enhancement of the coercivity of Nd-Fe-B magnets, with a slight sacrifice of remanence, was also demonstrated.

The positive effect of REM hydride additions to the powder mixture allows the possibility of introducing various components to the permanent magnets (heavy REMs, elements structuring grain boundaries and restricting the magnet grain growth) at the preparation stage rather than at the alloy-melting stage. This allows the possibility of using a unified initial alloy for the manufacture of magnets with high-coercive or high-performance characteristics.

\section{ACKNOWLEDGMENTS}

This study was carried out within the project "Development of physico-chemical and engineering foundations for the initiation of innovative resources-economy technology of high-power and highcoercivity (Nd,R)-Fe-B (R = Pr, Tb, Dy, Ho) low-REM permanent magnets", projects No. LTARF18031 


\section{funded by the Ministry of Education, Youth and Sports of the Czech Republic and No. 14.616.21.0093 (unique identification number: RFMEFI61618X0093) funded by the Ministry of Science and Higher Education of the Russian Federation.}

\section{REFERENCES}

[1] GUTFLEISCH, O., WILLARD, M.A., BRUCK, E. et al. Magnetic Materials and Devices for the $21^{\text {st }}$ Century: Stronger, Lighter, and More Energy Efficient. Advanced Material. 2011, vol. 23, pp. 821-842.

[2] SEPEHRI-AMIN, H., UNE, Y., OHKUBO, T., et al. Microstructure of fine-grained Nd-Fe-B sintered magnets with high coercivity. Scripta Materialia. 2011, vol. 65, no. 5, pp. 396-399.

[3] ZHANG, Y., MA, T., LIU, X., et al. Coercivity enhancement of Nd-Fe-B sintered magnets with intergranular adding (Pr, Dy, Cu)-Hx powders. Journal of Magnetism and Magnetic Materials. 2016, vol. 399, pp. 159-163.

[4] PAN, M., ZHANG, P., LI, X., GE, H., WU, Q., JIAO, Z. and LIU, T. Effect of Terbium addition on the coercivity of the sintered NdFeB magnets. Journal of Rare Earths. 2010, vol. 28, no. 1, pp. 399-402.

[5] KIANYASHI, A., MOTTRAM, R. S. and HARRIS, I. R. Densification of Nd13Fe78NbCoB7-type Sintered Magnet by (Nd, Dy)-Hydride Additions Using a Powder Blending Technique. Journal of Alloys and Compounds. 1999, vol. 287, pp. 206-214.

[6] BURKHANOV, G. S., KOLCHUGINA, N. B., LUKIN, A. A., KOSHKIDKO, Y. S., CWIK, J., SKOTNICOVÁ, K. and SITNOV, V. V. Role of Terbium Hydride Additions in the Formation of Microstructure and Magnetic Properties of Sintered Nd-Pr-Dy-Fe-B Magnets. Inorganic Materials: Applied Research. 2018, vol. 9, pp. 509-516.

[7] SKOTNICOVA, K., BURKHANOV, G.S., KOLCHUGINA, N.B., KURSA, M., CEGAN, T., LUKIN, A.A., ZIVOTSKY, O., PROKOFEV, P.A., JURICA, J., LI, Y. Structural and magnetic engineering of (Nd, Pr, Dy, Tb)-Fe-B sintered magnets with $\mathrm{Tb}_{3} \mathrm{Co}_{0.6} \mathrm{Cu}_{0.4} \mathrm{H}_{\mathrm{x}}$ composition in the powder mixture. Journal of Magnetism and Magnetic Materials. 2020, vol. 498, p. 166220.

[8] SKOTNICOVA, K., BURKHANOV, G. S., CEGAN, T., KOLCHUGINA, N. B., LUKIN, A. A., ZIVOTSKY, O., et al. Optimizing the microstructure of sintered $\mathrm{Nd}$-Fe-B magnets via the application of scandium hydride. IOP Conf. Series: Journal of Physics: Conference Series. 2018, vol. 1134, p. 012055.

[9] PROKOFEV, P., KOLCHUGINA, N. B., BURKHANOV, G. S., LUKIN, A. A., KOSHKID'KO, Y. S., SKOTNICOVA, K., CEGAN, T., ZIVOTSKY, O., KURSA, M.,et al. Multiphase characterization of phase equilibria in the Tb-rich corner of the Co-Cu-Tb system. Journal of Phase Equilibria and Diffusion. 2019, vol. 40, pp. 403-412.

[10] HONO K. and SEPEHRI-AMIN, H. Reprint of Prospect for HRE-free high coercivity Nd-Fe-B permanent magnets. Scripta Materialia. 2018, vol. 154, pp. 277-283.

[11] LI, W. F., SEPEHRI-AMINA, H., OHKUBO, T., HASE, N. and HONO, K. Distribution of Dy in high-coercivity (Nd,Dy)-Fe-B sintered magnet. Acta Materialia. 2011, vol. 59, pp. 3061-3069.

[12] KAWASAKI, K., YANAI, T., NAKANO, M. and FUKUNAGA, H. Computer Simulation of Enhancement of Coerciviy in Nd-Fe-B/(Nd,Dy)-Fe-B Composite Magnets. Journal of Magnetics. 2011, vol. 16, no. 2, pp. 145-149.

[13] COOK, B.A., HARRINGA, J.L., LAABS, F.C., DENNIS, K.W., RUSSELL, A.M., MCCALLUM, R.W. Diffusion of Fe, $\mathrm{Co}, \mathrm{Nd}$, and Dy in R2(Fe1-xCox)14B where R=Nd or Dy. Journal of Magnetism and Magnetic Materials. 2001, vol. 23, pp. 136-141.

[14] NISHIO, S., SUGIMOTO, S., GOTO, R., MATSUURA, M. and TEZUKA. N. Effect of Cu Addition on the Phase Equilibria in Nd-Fe-B Sintered Magnets. Materials Transactions. 2008, vol. 50, pp. 723-726.

[15] NISHIO, S., GOTO, R., MATSUURA, M., TEZUKA, N., SUGIMOTO, S. Wettability between Nd2Fe14B and NdRich Phase in Nd-Fe-B Alloy System. Journal of the Japan Institute of Metals. 2008, vol. 72, 1010-1014.

[16] PAN, M., GE, H.; ZHANG, P.; ZHU, J.; JIAO, Z.; ZHAO, Y. Effects of cobalt addition on the coercivity of sintered NdFeb magnets prepared by HD method. Zhongguo Xitu Xuebao. 2010, vol. 28, pp. 247-251.

[17] ZHONG, H., FU, Y., Li, G., LIU, T., CUI, W., LIU, W., ZHANG, Z., WANG, Q. Enhanced coercivity thermal stability realized in $\mathrm{Nd}-\mathrm{Fe}-\mathrm{B}$ thin films diffusion-processed by $\mathrm{Nd}-\mathrm{Co}$ Alloys. Journal of Magnetism and Magnetic Materials. 2017, vol. 426, pp. 550-553.

[18] KIM, T.-H., LEE, S.-R., NAMKUMG, S., JANG, T.-S. A study on the Nd-rich phase evolution in the Nd-Fe-B sintered magnet and its mechanism during post-sintering annealing. J. Alloys \& Comp. 2012, vol. 537, pp. 261268. 